\title{
RUPTURED POSTERIOR FOSSA ANEURYSMS AND THEIR SURGICAL TREATMENT*
}

\author{
BY \\ HELEN DIMSDALE and VALENTINE LOGUE
}

From the Maida Vale Hospital for Nervous Diseases, London

The use of vertebral angiography in the investigation of subarachnoid haemorrhage has enabled the presence of posterior fossa aneurysms to be detected during life. The clinical and radiological localization of aneurysms in this site is now of importance, for with modern neurosurgical techniques, including hypothermia, a number of these lesions are operable. Certain anatomical features which will be discussed later should render their surgical treatment in some ways easier than that of aneurysms in a supratentorial location.

Aneurysms in the posterior fossa are here defined as lying below the level of the tentorium and situated on the vertebral artery, the basilar artery, and their branches up to the basilar bifurcation. Aneurysms on the posterior cerebral artery and those presenting directly upwards from the termination of the basilar artery are not included, as they are truly aneurysms of the circle of Willis and have different symptoms and require an entirely different surgical approach compared with those situated below the tentorium.

Before, the use of vertebral angiography, the diagnosis of posterior fossa aneurysm was usually made at necropsy after death due to subarachnoid haemorrhage, or occasionally on surgical exposure, when an aneurysm had presented as a spaceoccupying lesion in the posterior fossa. Some aneurysms were symptomless in life, and then were accidental findings in death due to other causes.

The figures of incidence may be obtained from published series of cases of subarachnoid haemorrhage. McDonald and Korb (1939) reviewed 1,023 cases of intracranial aneurysm from the literature including 786 examples of rupture, and of those 143 $(18 \%)$ were on the basilar-vertebral trunks. Richardson and Hyland (1941) in a series of personal cases which contained 27 ruptured aneurysms, found that six, or $22 \%$, were in the posterior fossa. Walton (1956) included eight (6.5\%) among 122 ruptured

\footnotetext{
*Based on communications read at the Association of British Neurologists and the Society of British Neurological Surgeons, November, 1957.
}

aneurysms in the Newcastle series. The incidence $\overparen{\Phi}$ shows a tendency to a reduction in recent series which has been ascribed to exclusion of aneurysms ${ }^{\infty}$ due to syphilitic and atheromatous changes. Walsh $\vec{\circ}$ (1957) in a surgical series of cases of subarachnoid $\vec{\overrightarrow{ }}$ haemorrhage, found an incidence of $6 \%$ and $\omega$ attributed this lower figure to the fact that vertebral angiography was not carried out as a routine. An incidence of $15 \%$ on the basilar-vertebral circulation was accepted by Walton and Walsh, but if aneurysms $\omega$ of the posterior part of the circle of Willis webe i excluded, the figure would be about $10 \%$. त

Some information about the clinical aspects subarachnoid haemorrhage due to posterior fossa aneurysms may be found in the literature. Dand $?$ (1944) considered bilateral motor loss as evidence \&f으 haemorrhage from an aneurysm of the basilar of vertebral arteries. The late Sir Hugh Cairns (195) discussed the disturbance of consciousness associate of with disorders of the brain-stem. He quoted a case of subarachnoid bleeding into the posterior fossa due to a laterally situated aneurysm of the basilar artery, which produced homolateral pain in the head, followed by loss of consciousness with stertorous $\frac{\otimes}{\varnothing}$ breathing and four convulsive attacks, with recovery. $\triangle$ He considered that abrupt losses of consciousness, $\overrightarrow{\vec{O}}$ respiratory disturbances with hypersecretion of 3 mucus, and weakness of the legs were characteristic of dysfunction of the lower brain-stem.

Focal cranial nerve signs mentioned by Walton (1956) in his review of cases from the literature and the Newcastle series, included nystagmus, external $\frac{0}{3}$ rectus and facial palsies, premonitory attacks of vertigo, and deafness. Pain in the trigeminal $\delta$ territory was a common feature of aneurysms on the $₹$ internal carotid artery and its terminal branches, $\frac{\rho}{7}$ but ipsilateral headache was mentioned in one patient with a basilar aneurysm lying in the left cerebello-pontine angle. Contraction of the pupils, $\bar{N}$ although a well recognized feature of pontine 0 haemorrhage, was not stressed as a sign of aneurysms $N$ of the posterior fossa. Subarachnoid bleeding has $\underset{\omega}{\mathrm{W}}$ 
been observed by Robertson (1949) to cause convulsions, plastic disorders of tone, and fluctuating hemiparesis. He found that fits of a tonic type might result if blood clot formed on the ventral surface of the brain-stem. Brain (1955) considered that quadriplegia and various forms of "crossed paralyses" might occur due to a leaking basilar aneurysm, and that the head retraction was likely to be conspicuous when haemorrhage resulted from an aneurysm in the posterior fossa.

Accounts of surgical treatment usually consist of reports of a single case. Dandy (1944) wrote of a large aneurysm on the vertebral artery which was shelled out easily but the patient died from the effect of high pressure in the posterior fossa. Six successful operations have been reported. Schwartz (1948) described the excision of an aneurysm on an aberrant artery related to the internal auditory artery. Rizzoli and Hayes (1953) recorded one case of a posterior inferior cerebellar aneurysm. The patient presented with bilateral sixth nerve palsies and multiple subhyaloid haemorrhages in the fundi. The location of the aneurysm in the posterior fossa was suspected by the presence of hydrocephalus on ventriculography with a shift of the fourth ventricle to the right. The sac was completely excised with its segment of artery and a reasonable neurological recovery eventually followed. Norlén and Barnum in the same year described symptomatic relief after treatment of one large vertebral aneurysm by a decompression and packing with muscle, and also the successful excision of an aneurysm on the posterior inferior cerebellar artery in a man aged 26 who was alive and well six years later.

Two cases of aneurysm of the posterior inferior cerebellar artery treated surgically have been described by DeSaussure, Hunter, and Robertson (1958). The first patient, in addition to severe occipital headache, had unusual focal symptoms at the onset consisting of weakness and tingling of the left extremities with blurred vision in the left homonymous half-fields, which suggested spasm extending to the right posterior cerebral artery and circle of Willis. The authors in both cases adopted the procedure of "trapping" the aneurysm between proximal and distal clips with occlusion of the posterior inferior cerebellar artery. They considered that the mild ataxia which resulted was preferable to the risk of further haemorrhage.

Uihlein and Hughes (1955) reported exploration of 14 aneurysms on the basilar-vertebral system. Eight of the 14 patients died of aneurysmal rupture, but no definitive treatment was undertaken for these lesions.

Although factual information about these aneurysms is increasing, the view that posterior fossa arterial lesions are probably untreatable, still tends to influence our attitude to further investigation and to dissuade us from performing vertebral angiography routinely after negative carotid arteriograms. Walton (1956), after reviewing a variety of papers dealing with the surgical treatment of aneurysms, made the following statement: "Although occasionally posteriorly situated aneurysms have been operated upon with success, the great majority of those on the basilar and many on the vertebral and cerebellar arteries are not at present operable". Walsh (1957) also commented that "few cases of posterior fossa aneurysms are at present amenable to surgical treatment".

Theoretical considerations, however, suggest that these aneurysms should not present insuperable technical difficulties. First because they are primarily "subarachnoid" aneurysms lying free in the subarachnoid space, so that little retraction of brain is necessary to expose them. Secondly both vertebral arteries are visible for most of their course through a posterior fossa approach, and there is a good deal of room for surgical manoeuvre. The whole length of the basilar artery can be clearly seen by a transtentorial approach, the only limiting factor being the fifth, seventh, and eighth cranial nerves which can to some extent be moved out of the way. Finally when treating aneurysms on the vertebral artery and its branches, there is always the opposite vertebral artery to maintain blood flow should it be necessary to occlude the vessel.

\section{Case Material}

In view of the rather negative attitude towards surgical treatment, it was felt worth while to record six consecutive cases of ruptured posterior fossa aneurysm operated on successfully.

A second group of six cases selected at random has been included in the series for the purpose of obtaining further examples of the localizing signs of subarachnoid haemorrhage in this situation. Five were obtained from past records at the Atkinson Morley Hospital and are included by kind permission of Mr. Wylie McKissock, and one case came to necropsy at Maida Vale Hospital. It must be stressed that Group II are not to be regarded as a control series medically treated.

The situations of the aneurysms in Groups I and II are shown in Table I.

The cases in Group I are illustrated in line drawings of vertebral arteriograms (Fig. 1).

The vertebral trunk in the region of the origin of the posterior inferior cerebellar artery was the commonest site. No significant predominance with regard to side was shown by the whole series. 


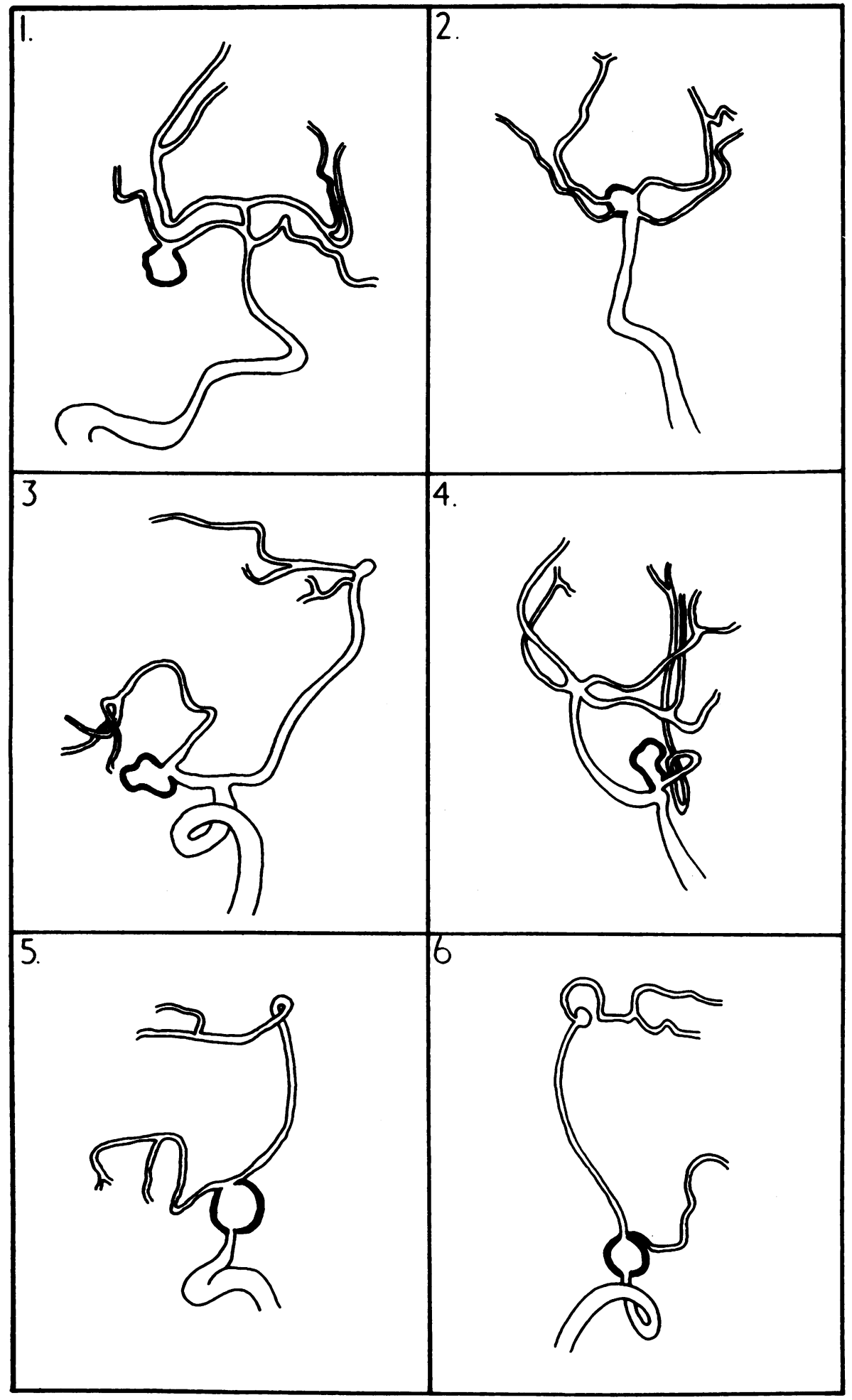

FIG. 1.-Vertebral arteriograms of the six patients submitted to surgery.

Case 1 (C.G.).-Antero-posterior projection to show the aneurysm on the right superior cerebellar artery.

Case 3 (J.R.).-Lateral view showing a large aneurysm with a broad neck on the posterior inferior cerebellar artery.

Case 5 (M.K.).-Lateral view. The aneurysmal sac consists of a dilatation of the vertebral arterial trunk; the posterior inferior cerebellar artery arises from the apex of the aneurysm with the distal trunk of the vertebral.
Case 2 (C.C.).-Antero-posterior view. The aneurysm arises from the right side of the basilar artery and gives origin to the posterior cerebral and superior cerebellar trunks.

Case $4(C . H$.). - Oblique view to show the bilocular aneurysm arising directly from the vertebral artery in conjunction with the origin of the posterior inferior cerebellar branch.

Case 6 (P.McM.).-Lateral view showing the sac which consists of a dilatation of the vertebral artery just within the foramen magnum. The posterior inferior cerebellar artery has the same relationship to the sac as in Case No. 5 . 
TABLE I

SITE OF ANEURYSMS

\begin{tabular}{|c|c|c|c|c|}
\hline & \multicolumn{2}{|r|}{ Case } & Side & Situation \\
\hline Group I & $\begin{array}{l}1 \\
2 \\
3 \\
4 \\
5 \\
6\end{array}$ & $\begin{array}{l}\text { C.G. } \\
\text { C.C. } \\
\text { J.R. } \\
\text { C.H. } \\
\text { M.K. } \\
\text { P.McM.M. }\end{array}$ & $\begin{array}{l}\text { Right } \\
\text { Left } \\
\text { Left } \\
\text { Left } \\
\text { Right } \\
\text { Left }\end{array}$ & $\begin{array}{l}\text { Superior cerebellar artery } \\
\text { Basilar at origin of superior cerebellar and posterior cerebral arteries } \\
\text { Posterior inferior cerebellar artery } \\
\text { Aneurysm arising by neck from the vertebral artery } \\
\text { On the vertebral artery as localized saccular dilatation } \\
\text { On the vertebral artery as localized saccular dilatation }\end{array}$ \\
\hline \multicolumn{5}{|c|}{ Cases 4,5 , and 6 all closely related to the origin of the posterior inferior cerebellar artery } \\
\hline Group II & $\begin{array}{r}7 \\
8 \\
9 \\
10 \\
11 \\
12\end{array}$ & $\begin{array}{l}\text { D.S. } \\
\text { G.S. } \\
\text { V.S. } \\
\text { R.R. } \\
\text { E.J. } \\
\text { J.D. }\end{array}$ & $\begin{array}{l}\text { Left } \\
\text { Left } \\
\text { Middle } \\
\text { Right } \\
\text { Left } \\
\text { Right }\end{array}$ & $\begin{array}{l}\text { Basilar at origin of superior cerebellar and posterior cerebral arteries } \\
\text { Anterior inferior cerebellar artery } \\
\text { Basilar artery } \\
\text { Vertebral basilar junction } \\
\text { Posterior inferior cerebellar artery } \\
\text { Posterior inferior cerebellar artery }\end{array}$ \\
\hline
\end{tabular}

\section{Clinical Features}

The present series showed a slight female preponderance of eight females to four males (Table II). The ages at time of the subarachnoid haemorrhage ranged from 35 to 68 , and eight of the 12 patients were between the ages of 40 and 60 , the age period of maximal incidence for this disorder. The sex and age distribution did not differ therefore from that in subarachnoid haemorrhage from supratentorial aneurysms.

TABle II

CLINICAL FEATURES

\begin{tabular}{|c|c|c|c|c|c|c|c|c|c|c|c|c|c|c|c|}
\hline$\therefore$ & & Case & $\begin{array}{c}\text { Site of } \\
\text { of } \\
\text { Aneurysm }\end{array}$ & Bleeds & $\begin{array}{c}\text { Disturbance } \\
\text { of } \\
\text { Conscious- } \\
\text { ness }\end{array}$ & Fundi & Pupils & $\begin{array}{c}\text { External } \\
\text { Ocular } \\
\text { Move- } \\
\text { ments }\end{array}$ & 5th & 7 th & 8 th & Limbs & $\begin{array}{c}\text { Plan- } \\
\text { tars }\end{array}$ & $\begin{array}{c}\text { Opera- } \\
\text { tion } \\
\text { Day } \\
\text { Taken } \\
\text { since } \\
\text { Last } \\
\text { Bleed }\end{array}$ & Result \\
\hline 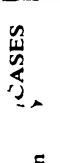 & 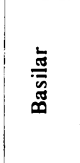 & $\begin{array}{l}1 . \dot{ } \\
\text { C.G. } \\
+56 \\
2 . \\
\text { C.C. } \\
749\end{array}$ & $\begin{array}{l}\text { R. sup. } \\
\text { cerebellar } \\
\text { L. sup. } \\
\text { cerebellar } \\
\text { Post. } \\
\text { cerebral }\end{array}$ & $\begin{array}{l}4 \\
1\end{array}$ & $\begin{array}{l}\text { I fit } \\
4 \text { comas } \\
\text { Confused }\end{array}$ & & Dilated & R. 6th & $\begin{array}{l}\text { R.pain } \\
\text { and } \\
\text { sensory } \\
\text { loss }\end{array}$ & \begin{tabular}{l}
\multicolumn{1}{c|}{ L. } \\
upper \\
motor \\
neurone
\end{tabular} & $\begin{array}{l}\mathbf{R} . \\
\text { deaf }\end{array}$ & $\begin{array}{l}\text { L. hemi- } \\
\text { paresis } \\
\text { L. upper } \\
\text { limb all } \\
\text { jerks + }\end{array}$ & $\uparrow \downarrow$ & $\begin{array}{l}16 \mathrm{th} \\
15 \mathrm{th}\end{array}$ & Recover \\
\hline 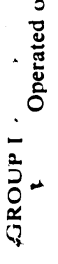 & 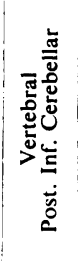 & $\begin{array}{c}3 . \\
\text { J.R. } \\
\delta 35 \\
4 . \\
\text { C.H. } \\
f 50 \\
5 . \\
\text { M.K. } \\
q 47 \\
6 . \\
\text { P.McM. } \\
\text { o } 55\end{array}$ & $\begin{array}{l}\text { L. post. inf. } \\
\text { cerebellar } \\
\text { L. } \\
\text { Vertebral } \\
\text { R. } \\
\text { Vertebral } \\
\text { L. } \\
\text { Vertebral }\end{array}$ & $\begin{array}{l}4 \\
1 \\
4 \\
2\end{array}$ & $\begin{array}{l}1 \text { collapse } \\
1 \text { fit } \\
1 \text { collapse } \\
\text { Coma } 2 \text { hr. } \\
\text { Semicoma } \\
12 \mathrm{hr} \text {. } \\
3 \mathrm{fits} \\
\text { Coma } 1 \mathrm{hr} \text {. } \\
\text { Semicoma } \\
36 \mathrm{hr} \text {. }\end{array}$ & $\begin{array}{c}\text { Haem } \\
++\end{array}$ & $\begin{array}{l}\text { Transient } \\
\text { unequal } \\
\text { contracted } \\
\text { R. miosis }\end{array}$ & $\begin{array}{l}\text { Transient } \\
\text { nystagmus } \\
\text { Ptosis } \\
\text { Transient } \\
\text { nystagmus } \\
\text { Ptosis } \\
\text { L. 6th } \\
\text { nystagmus }\end{array}$ & $\begin{array}{l}\text { Contra- } \\
\text { lateral } \\
\text { pain } \\
\text { P.H. } \\
\text { L. pain } \\
\text { Painful } \\
\text { par- } \\
\text { aesthesiae }\end{array}$ & \begin{tabular}{|l|}
$\mid$ \\
L \\
upper \\
motor \\
neurone
\end{tabular} & \begin{tabular}{|l|} 
Vertigo \\
Vertigo
\end{tabular} & $\begin{array}{l}\text { Weakness } \\
\text { legs } \\
\text { Weak legs } \\
\text { Sensory } \\
\text { loss } \\
\text { R. then L. } \\
\text { hemi- } \\
\text { paresis } \\
\text { Weak legs } \\
\text { L. hemi- } \\
\text { paresis }\end{array}$ & $\begin{array}{l}\uparrow \uparrow \\
\uparrow \uparrow\end{array}$ & $\begin{array}{l}\text { 2nd } \\
19 \text { th } \\
12 \\
\text { hours } \\
10 \text { th }\end{array}$ & $\begin{array}{l}\text { Recovery } \\
\text { Recovery } \\
\text { Recovery } \\
\text { Recovery }\end{array}$ \\
\hline 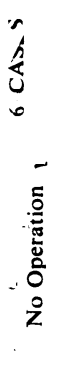 & $\frac{\overline{7}}{\bar{a}}$ & 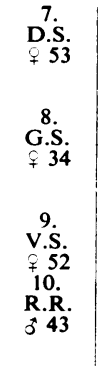 & $\begin{array}{l}\text { L. sup. } \\
\text { cerebellar } \\
\text { Post } \\
\text { cerebral } \\
\text { L. ant. inf. } \\
\text { and sup. } \\
\text { cerebellar } \\
\text { Mid } \\
\text { basilar } \\
\text { ?R. vert. } \\
\text { and basilar }\end{array}$ & $\begin{array}{c}\begin{array}{l}1 \\
\text { fatal }\end{array} \\
3\end{array}$ & $\begin{array}{l}\text { Semicoma } \\
\text { Deep } 2 \mathrm{hr} \text {. } \\
\text { Semicoma } \\
\text { Coma } 12 \mathrm{hr} \text {. } \\
\text { recovered } \\
\text { Uncon. } 15 \\
\text { min. } \\
\text { Fit 4th day } \\
\text { Found } \\
\text { unconscious } \\
1 \text { fit uncon. } \\
30 \text { min. } \\
\text { Uncon. 1 hr. } \\
\text { on } 11 \text { th day }\end{array}$ & $\begin{array}{l}\text { Haem. } \\
\text { and } \\
\text { Papill- } \\
\text { oedema }\end{array}$ & $\begin{array}{l}\text { Dilated } \\
\text { Unequal } \\
\text { Fixed }\end{array}$ & Ptosis & $\begin{array}{l}\text { P.H. } \\
\text { L. pain }\end{array}$ & $\begin{array}{l}\mathrm{R} . \\
\text { upper } \\
\text { motor } \\
\text { neurone }\end{array}$ & & $\begin{array}{l}\text { Weak legs } \\
\text { t onset } \\
\text { L. spastic } \\
\text { hemi- } \\
\text { paresis } \\
\text { L. hemi- } \\
\text { paresis } \\
\text { Twitching } \\
\text { R. arm } \\
\text { Flaccid } \\
\text { quadri- } \\
\text { plegia } \\
\text { R. hemi- } \\
\text { paresis }\end{array}$ & $\begin{array}{l}\downarrow \downarrow \\
\uparrow \uparrow\end{array}$ & $\begin{array}{l}\text { Chest infe } \\
\text { Death } \\
\text { 5th day of } \\
\text { Death } \\
\text { 6th day }\end{array}$ & $\begin{array}{l}\text { ction } \\
\text { illness }\end{array}$ \\
\hline $\begin{array}{l}\bar{a} \\
\stackrel{a}{\partial} \\
0 \\
\stackrel{\alpha}{c}\end{array}$ & 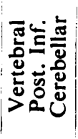 & $\begin{array}{l}\text { 11. } \\
\text { E.J. } \\
+68 \\
12 . \\
\text { J.D. } \\
\sigma 62\end{array}$ & $\begin{array}{l}\text { L. vert. and } \\
\text { post inf. } \\
\text { cerebellar } \\
\text { R. vert. and } \\
\text { post. inf. } \\
\text { cerebellar }\end{array}$ & 2 & $\begin{array}{l}\text { Coma } 12 \mathrm{hr} . \\
\text { Drowsy } \\
\downarrow \\
\text { Coma }\end{array}$ & Haem. & $\begin{array}{l}\text { Contracted } \\
\text { Contracted }\end{array}$ & $\begin{array}{l}\text { Bilateral } \\
\text { 6th } \\
\text { Contra- } \\
\text { lateral } \\
\text { 6th }\end{array}$ & & $\begin{array}{l}\text { R. } \\
\text { upper } \\
\text { motor } \\
\text { neurone }\end{array}$ & Leaf & $\begin{array}{l}\text { R. hemi- } \\
\text { paresis } \\
\text { Weak legs } \\
\text { L. > R. }\end{array}$ & $\uparrow \uparrow$ & $\begin{array}{l}\text { Death } \\
\text { 7th day }\end{array}$ & \\
\hline
\end{tabular}




\section{Symptoms and Signs}

Weakness of the Legs. - This or sudden falling was an initial symptom in five patients. The loss of power was not infrequently transient and might improve before the patient was prostrated by headache. One patient (Case 3) stopped driving his car because of leg weakness and nausea before the usual symptoms of subarachnoid haemorrhage developed a quarter of an hour later. Case 6, a man aged 55, after mild headache for four days suddenly vomited and lost the use of his legs. A woman (Case 4) "flopped" to the floor during a dancing lesson because her legs gave way. Another woman (Case 7) was found by her husband holding herself up by the sink, and did not develop headache till some hours later. A man aged 62 (Case 12) suddenly developed weakness of the left leg, which then spread to the right and was followed by headache and vomiting.

Headache.-Headache was an early symptom in every patient except one (Case 8 ) who lost consciousness immediately and died in coma. A period of mild headache for several days might be followed by a severe exacerbation with signs of meningeal irritation, indicating a frank haemorrhage. The intense headache was usually occipital at the onset but then became generalized, spreading over the head to the frontal region. The accompanying neck rigidity was usually of moderate degree, and head retraction was exceptional. Localization of pain in the region of the ear on the same side as the aneurysm was observed in two patients, in one (Case 1) associated with an aneurysm on the superior cerebellar artery, and in the other (Case 5) with an aneurysm on the vertebral artery. A past history of frontal headache regarded as migraine was given by three patients (Cases 1, 4, and 5). Case 4 had experienced trigeminal neuralgia on the side of the aneurysm. Sensory disturbance in the trigeminal territory in Cases 1 and 5 accompanied actual rupture. However, lateralization of the aneurysm by the site of the pain at the onset of haemorrhage was not always reliable. One man, aged 35 (Case 3), had experienced right-sided headache for a month, and at the time of the ictus complained of an intense exacerbation, but the aneurysm was situated on the left vertebral artery.

Loss of Consciousness. - The initial loss of consciousness might be of sudden onset and of up to 36 hours' duration followed by recovery of the senses. The patient then might become alert and cooperative (Cases 3, 8, and 11). A noticeable feature of the disorder in seven patients was that of brief depressions in the level of consciousness, followed by rapid improvement, and five of these patients (Cases 1, 3, 5, 8, and 10) also experienced convulsive episodes.

A woman, aged 47 (Case 5), had an epileptiform attack with jerking movements of the arms and stertorous breathing at the onset of the haemorrhage, and later in her illness two generalized convulsions with "bubbly" respiration, followed by a transient flaccid hemiplegia. One man (Case 3) lost consciousness on the eighth day of illness with frothing at the mouth. Later on the same day, on recovery from anaesthesia for carotid and vertebral angiography, he collapsed again with slow stertorous breathing. The pupils were contracted and both plantar responses became extensor. The supraorbital nerve was compressed to assess the depth of coma, at which stimulus he suddenly showed free movement of the limbs, recovered consciousness, became loquacious and said he felt fine. Presumably on this occasion the rapid change in his condition was due to spasm of the basilar artery, followed by return of the circulation. Stertorous respiration and hypersecretion of mucus were prominent in these attacks, and were also observed in another patient (Case 10) accompanied by protrusion of the tongue. A focal adversive attack occurred in one patient, and focal seizures in the arm in another with evidence of fresh haemorrhage.

Recurrent Haemorrhage.-Recurrences of haemorrhage, as judged by increase of headache, deterioration in the level of consciousness, and fresh blood in the cerebrospinal fluid were a common feature of these aneurysms, and eight patients (Cases 1, 3, 5, 6, $7,8,10$, and 12) together had 25 haemorrhages. A fatal outcome or crippling neurological disability did not necessarily result. Three patients (Cases 1 , 3 , and 5) each had four haemorrhages, yet survived operation.

Fundus Oculi.-Retinal or subhyaloid haemorrhages were seen in four patients (Cases 5, 8, 11, 12). One woman (Case 5) had gross bilateral subhyaloid haemorrhages due to a subarachnoid haemorrhage from a right vertebral aneurysm. Papilloedema was present in three patients (Cases 7, 8, and 10), one of whom (Case 8) showed papilloedema on the same side as the haemorrhage and a vitreous haemorrhage in the other eye.

Cranial Nerve Signs. - Abnormalities of the pupils and ocular movements were the commonest defect of the cranial nerves. Bilateral contraction of the pupils was observed in five patients (Cases 3, 6, 7, 11, and 12) and unequal pupils in three (Cases 3, 4, and 9). Two patients (Cases 2 and 9) showed widely dilated pupils which were also inactive in the latter 
patient (Case 9) who subsequently died. Sixth nerve palsies, which might be unilateral or bilateral, occurred in four patients (Cases 1, 6, 11, and 12). When unilateral, the palsy was not of value as a lateralizing sign unless associated with palsies of neighbouring cranial nerves as in one patient (Case 1) with trigeminal and eighth nerve lesions in addition. Three patients showed ptosis (Cases 4, 5, and 7), and three (Cases 3, 4, and 6) nystagmus which appeared at the onset of the haemorrhage as a transient feature, but was sustained in one patient (Case 6) on lateral deviation towards the side of the lesion, a vertebral aneurysm.

Paraesthesiae in the trigeminal territory in one patient (Case 5), and cutaneous sensory loss in another (Case 1) developed on the same side as the ruptured aneurysm. Symptoms referable to the eighth nerve consisted of rotatory vertigo (Cases 4 and 5), and two other patients (Cases 1 and 11) became deaf on the side of the ruptured aneurysm.

A contralateral facial paresis of an upper motor neurone type was observed in four patients (Cases 1, 5,10 , and 11) associated with a hemiparesis.

Signs in the Limbs. - These were bilateral in 10 patients (Cases 1, 2, 4, 5, 6, 7, 8, 9, 10, and 12). Evidence of pyramidal disturbance was found in all the patients at some time in their illness, though in one (Case 3) only after a fit when bilateral extensor plantar responses appeared. Weakness of the legs as mentioned before occurred as an initial symptom in five patients.

A unilateral hemiparesis (Cases 6, 8, 10, and 11) or alternating hemiparesis (Cases 5 and 7) might appear in association with a sudden loss of consciousness or convulsive episode. These hemipareses were often transient leaving only slightly increased tendon reflexes. A total flaccid paraplegia was present until death in a haemorrhage due to rupture of a mid-basilar aneurysm. The plantar response was extensor in character in 10 patients, and in seven of these the abnormality was bilateral. A "crossed" paralysis or hemiplegia was observed in two patients (Cases 1 and 11) with cranial nerve lesions on one side and pyramidal signs in the opposite limbs. Sensory loss in the limbs, as in most cases of subarachnoid haemorrhage was uncommon; one patient (Case 4) showed impaired appreciation of temperature contralaterally and absent vibration sense in the leg on the side of a vertebral aneurysm.

\section{Investigations}

The cerebrospinal fluid pressure in the early hours after the subarachnoid haemorrhage was available in nine cases. The level was not of a high order initially, and in five patients was $200 \mathrm{~mm}$. or less, though later, especially in the fatal recurrences, levels of $300 \mathrm{~mm}$. and over developed (Table III).

TABLE III

CEREBROSPINAL FLUID PRESSURE

\begin{tabular}{c|c}
\hline C.S.F. Pressure in mm. & Case No. \\
\hline Normal & 5 and 7 \\
150 to 200 & 2,6 and 8 \\
210 to 250 & 1,3, and 12 \\
300 & 10 \\
\hline
\end{tabular}

Although subhyaloid haemorrhages are usually attributed to haemorrhage from an anteriorly situated aneurysm, or to a sudden rise in cerebrospinal fluid pressure sufficient to occlude the central retinal veins, there did not seem a correlation between the presence of these changes in the fundi and the cerebrospinal fluid pressure at lumbar puncture. Widespread subhyaloid haemorrhages were present in both eyes in one patient (Case 5) when the cerebrospinal fluid pressure was $140 \mathrm{~mm}$. Another (Case 8) showed a right vitreous haemorrhage and left-sided papilloedema with a cerebrospinal fluid pressure of $200 \mathrm{~mm}$.

Electroencephalography (E.E.G.).-Electroencephalographic recordings were carried out in four patients (Cases 2, 3, 4, and 5). Similar E.E.G. abnormalities were observed in those patients (Cases 2, 4, and 5) with haemorrhage due to rupture of an aneurysm arising close to the basilar-vertebral trunk. The abnormalities consisted of periodic bursts of generalized slow waves in the frontal and occipital leads occurring at intervals of 10 to 60 seconds and lasting one to two seconds. The amplitude of the slow-wave bursts was greatest in Case 2, a patient with a relatively small aneurysm, but which arose directly from the anterior end of the basilar artery.

The phenomenon of periodic bursts of generalized slow waves has been described by other authors including Tucker (1958) in lesions of the brainstem.

Radiology.-Bilateral carotid angiography was employed in 11 patients without revealing the aneurysm, and right carotid angiography repeated on another occasion in Case 1 showed no abnormality. In Group I unilateral vertebral angiography, lateralized on clinical features in three patients (Cases 1, 5, and 6), filled the aneurysm successfully. Bilateral vertebral angiography was required in three patients. In Case 2 vertebral angiography on one side was unsuccessful, but the basilar aneurysm filled satisfactorily from the other vertebral. In Case 3, a man with severe right-sided facial pain, the right vertebral artery was injected first due to the 
false localization by facial pain and the basilar artery filled without showing the aneurysm on the left posterior inferior cerebellar artery. In Case 4, spasm of the intracranial vessels and irregularity of the right vertebral artery was observed but injection of the opposite vertebral artery revealed the aneurysm on the left posterior inferior cerebellar artery.

Post-operative angiography in Group I was carried out, except in those patients where proximal ligature of one vertebral artery had been employed (Cases 5 and 6), as spasm of the remaining patent vertebral artery might well have endangered the basilar circulation.

Vertebral angiography was performed in two patients (Cases 10 and 11) in Group II; in Case 10 the result was equivocal, in Case 11 bilateral vertebral angiography showed a tortuous basilar artery and a small aneurysm on the left posterior inferior cerebellar artery.

Ventricular dilatation was observed in three patients (Cases 3, 7, and 11). Wide-swept anterior cerebral arteries on carotid angiography in Case 7 indicated enlargement of the ventricles. Ventriculography in Case 3, a man aged 35, who developed ataxia and dementia after subarachnoid haemorrhage from a posterior inferior cerebellar aneurysm, showed generalized ventricular dilatation due to a communicating hydrocephalus. A slight ventricular dilatation was found in Case 11, a woman aged 68, on whom air studies were carried out to exclude the presence of a clot when a hemiparesis developed.

Carotid angiography, although it might reveal a complicating ventricular dilatation, was not of assistance in visualizing these aneurysms. If unilateral vertebral angiography was negative in Group I cases, the opposite vertebral artery was injected; otherwise it was found that an aneurysm on a vertebral artery at the usual site in proximity to the origin of the posterior inferior cerebellar artery might be missed.

Ventriculography was required to detect the presence of hydrocephalus resulting from interference with circulation of cerebrospinal fluid by adhesions in the posterior fossa.

\section{Surgery of Posterior Fossa Aneurysms}

The principles of surgical treatment of aneurysms in this location are similar to those which apply to the supratentorial aneurysms. Thus the method of election consists of the occlusion by clip or ligature of the neck of the aneurysm without interference with the patency of the parent vessel, as was achieved in Cases 3 and 4. When the aneurysm arises from what is considered to be an expendable artery the sac with its segment of vessel may be completely excised, as in the case reported by Schwartz in 1948 and in Case 1 of this series. The related procedure of "trapping" the aneurysm by a clip on the artery, both proximal and distal to the origin of the sac, is also a feasible one for dealing with saccular dilatations of the vertebral artery. This method was considered for Cases 5 and 6 , but the fact that in both these patients the posterior inferior cerebellar artery took origin directly from the apex of the sac precluded the manoeuvre. A clip on the vertebral artery proximal to the sac had to suffice, and was successful in preventing further bleeding.

Some doubt has been cast on the efficacy of this method of proximal occlusion of the vertebral artery for saccular dilatations of its trunk by the experimental work of Bakay and Sweet (1953) and has been quoted by other authors. Their investigation consisted of acute experiments (the number of which was not stated in the article) carried out during the course of operations on patients with posterior fossa lesions. The vertebral artery was occluded outside the skull between the occiput and atlas, measurements of the blood pressure then being recorded from the vertebral artery and posterior inferior cerebellar artery, using a very fine needle and electromanometer. The authors concluded that ligation of the vertebral artery on one side did not produce an adequate drop in pressure in the vessel for treatmen $\mathbb{b}$ of an aneurysm providing the opposite vertebrat trunk was of approximately the same size.

Whether the results of brief occlusions of theo vertebral artery in patients under full anaesthesiar. can be compared with the long-term pressure $\mathcal{O}$ changes following vertebral clipping in patients with normal vascular tone, or even increased tone following a subarachnoid haemorrhage, is open to serious question.

Certain practical observations made at operation in the present series are relevant to this discussion. Thus when the vertebral artery is clipped, the aneurysmal sac is left situated at the end of a long cul-de-sac in which the blood flow is reversed. At operation on the two patients in this series (Cases 5 and 6) when the vertebral artery was occluded the aneurysmal sac was seen to decrease considerably in size and the amplitude of its pulsation diminished. In both patients following this procedure ischaemic brain-stem symptoms developed and there can be no greater proof than this that proximal occlusion influenced the blood supply. Finally in both the patients there has been no repetition of the haemorrhage post-operatively, and one of them had had repeated severe bleeds.

It would seem therefore from actual surgical experience that occlusion within the skull of a vertebral artery proximal to a ruptured saccular dilatation is an effective method of treatment, and 
that in practice the real danger lies in the production of an excessive fall in blood pressure with subsequent ischaemia of the brain-stem, although it was recoverable in both these patients. The risk of thrombosis of the basilar artery following vertebral ligation must be mentioned, as this has been considered a contraindication by DeSaussure and his colleagues (1958). The recent case discussed by them in which this complication occurred was described by French and Haines (1950) and was not comparable, as the vertebral-basilar circulation was hypertrophied to supply a vascular meningioma.

Another method of treatment consists of wrapping a sheet of muscle round the aneurysm. This technique was adopted in Case 2, because both the posterior cerebral and superior cerebellar arteries on the same side were found to arise from the sac, and it was considered that occlusion of the aneurysm with these two vessels carried too high risk of infarction. If for anatomical reasons other methods are not practical, this procedure may occasionally be indicated.

Surgical Approach.-The six patients in this series were all operated upon in the sitting position in a surgical chair utilizing conventional anaesthetic technique, except for Case 4 , the most recent case chronologically, in which hypothermia was also induced.

Two methods of surgical approach were adopted.

Aneurysms on the vertebral arteries and their branches were explored through a unilateral posterior fossa craniectomy, and even in Case 4 where the sac was shown by arteriography to be situated far anteriorly in the fossa, relatively little difficulty in access was experienced.

On the other hand, aneurysms on the basilar and superior cerebellar artery were visualized by a transtentorial approach. This was carried out through a craniotomy flap exposing the posterior, temporal, and occipital regions. This area of brain was then elevated, as far as possible preserving the veins draining into the superior petrosal sinus, the tentorium then being incised a few millimetres behind its petrous attachment and avoiding damage to the fourth nerve. On retracting the cerebellar hemisphere the basilar artery and its branches could then be clearly seen, the only obstruction to exposure being the fifth, seventh, and eighth cranial nerves, and in Case 1 the fifth nerve had to be divided in order to mobilize the sac on the superior cerebellar artery.

One disadvantage of this approach was that a homonymous hemianopia invariably resulted, but cleared up in one to three weeks.

Time for Surgery.-The principle that arteriography and operation should be performed as soon after the haemorrhage as the patient's condition permits was followed as far as possible. However, as will be seen from Table IV, the time that elapsed between the last haemorrhage and operation varied from 12 hours in Case 5 to 19 days in Case 4. The longer intervals were mainly caused by the wait between the performance of the carotid and the vertebral arteriograms, and in three of these six patients it should be noted that further haemorrhages occurred during this interval.

Early diagnosis is important in the management of these patients. Ruptured posterior fossa aneurysms bleed repeatedly and are dangerous due to the risk of infarction of the pons, haemorrhage into the brain-stem and cerebellum, and organization of blood clot in the posterior fossa. Although

TABLE IV

OPERATIVE RESULTS

\begin{tabular}{|c|c|c|c|c|c|c|c|c|}
\hline Case & $\begin{array}{l}\text { Day } \\
\text { of } \\
\text { Illness }\end{array}$ & $\begin{array}{c}\text { Interval } \\
\text { since } \\
\text { Last } \\
\text { Bleeds }\end{array}$ & $\begin{array}{l}\text { No. } \\
\text { of } \\
\text { Bleeds }\end{array}$ & $\begin{array}{l}\text { Condition } \\
\text { at } \\
\text { Operation }\end{array}$ & Convalescence & Interval & Activity & Residual Defects \\
\hline C. $\dot{\text { G. }}$ & $21 \mathrm{st}$ & $\begin{array}{c}16 \\
\text { days }\end{array}$ & 4 & Good & Uninterrupted & $\begin{array}{c}7 \\
\text { years }\end{array}$ & Full & $\begin{array}{l}\text { 5th sensory loss following section at } \\
\text { operation. Slight contracture homo- }\end{array}$ \\
\hline C.C. & 15 th & $\begin{array}{c}15 \\
\text { days }\end{array}$ & 1 & Good & Uninterrupted & $\begin{array}{c}18 \\
\text { months }\end{array}$ & Full & None \\
\hline J. & 9 th & $\begin{array}{c}2 \\
\text { days }\end{array}$ & 4 & Poor & $\begin{array}{l}\text { Dementia due to communi- } \\
\text { cating hydrocephalus }\end{array}$ & $\underset{\text { years }}{2}$ & $\begin{array}{l}\text { Light } \\
\text { work }\end{array}$ & $\begin{array}{l}\text { Nystagmoid jerks. Slight difficulty } \\
\text { in balancing on one leg }\end{array}$ \\
\hline C. & 19 th & $\begin{array}{c}19 \\
\text { days }\end{array}$ & 1 & Good & Uninterrupted & $\begin{array}{l}1 \\
\text { year }\end{array}$ & Full & Initial weakness of left trapezius \\
\hline M.K. & 9 th & $\begin{array}{l}12 \\
\text { hours }\end{array}$ & 4 & Poor & $\begin{array}{ll}\text { Difficult. } & \text { Brain-stem } \\
\text { ischaemia. } & \text { Tracheotomy }\end{array}$ & $\begin{array}{l}18 \\
\text { months }\end{array}$ & Impaired & Low visual acuity. Ataxia of gait \\
\hline P.M.M & $10 t h$ & $\begin{array}{c}10 \\
\text { days }\end{array}$ & 2 & Fair & $\begin{array}{l}\text { Difficult } \\
\text { Brain-stem ischaemia } \\
\text { Tracheotomy for respiratory } \\
\text { infection }\end{array}$ & $\stackrel{2}{\text { years }}$ & $\begin{array}{l}\text { Light } \\
\text { work }\end{array}$ & $\begin{array}{l}\text { Horizontal nystagmus } \\
\text { Reduction of cutaneous sensibility } \\
\text { below knee of } R \text {. leg. Joint sense } \\
\text { impaired in toes }\end{array}$ \\
\hline
\end{tabular}


the disturbances of consciousness and limb pareses may be transient, the patient's mentality and general condition deteriorate with each bleed and chest infection tends to supervene.

Cases 3 and 5 were operated on the ninth day of illness, the former two days and the latter 12 hours after a fourth haemorrhage. Both were gravely ill at the time of operation and had difficult postoperative periods. Case 3 remained confused with marked intellectual deterioration due to a communicating hydrocephalus which required anterior ventriculostomy. Some circulatory disturbance may already have been present in Case 5 as she had had two convulsions with bubbly respiration and transient hemipareses 12 hours before operation. She developed symptoms of bulbar ischaemia postoperatively from which she made a slow recovery and was left with some ataxia of gait. Visual failure due to subhyaloid haemorrhages is another danger of delay, but in Case 5 the damage occurred after the first haemorrhage.

Even in gravely ill patients the level of consciousness and vital functions after a bleed usually recover to a stage at which neurosurgery can be undertaken. Repeated lumbar puncture may be useful.

As will be seen from the abstract of results (Table IV) good condition at the time of operation and absence of significant cranial nerve or other pareses are the features which assist in obtaining a satisfactory operative result.

A greater awareness of the clinical features of haemorrhage due to posterior fossa aneurysms would lead to the diagnosis being suspected at an earlier stage, so that vertebral angiography could be employed without unnecessary delay. The problem whether carotid angiography can be omitted in selected cases will be considered in the discussion.

\section{Discussion}

Certain clinical features of the ictus require explanation, such as the absence of signs of cerebellar disturbance, apart from nystagmus, when an aneurysm associated with one of the cerebellar arteries has ruptured. Elkington (1958) has attributed the rarity of frank cerebellar symptoms in basilar occlusion to the rich anastomoses between several vessels in this organ or because of its relative insensitivity to anoxia. Perhaps in aneurysmal lesions previous ischaemia in the territory of the affected vessel has resulted in the opening up of collateral supplies, or compensatory mechanisms have developed as in other slowly growing cerebellar lesions. The midline cerebellar syndrome with truncal ataxia might not be detected in these seriously ill patients who cannot be mobilized.
Kremer (1958) regards weakness and collapse of the legs at the onset as a manifestation of disturbance of the cerebellar connexions in the brain-stem knocking out the Y-fibre servo loops.

The severity of the subhyaloid haemorrhages may be surprising as the source of the bleeding is posteriorly situated and the cerebrospinal fluid pressure is not invariably high. It is important to realize their occurrence, otherwise delay in diagnosing posterior fossa aneurysms may result from repeated carotid angiography or attempts to find other causes, such as a haemorrhagic diathesis, before vertebral angiography is undertaken.

Haemorrhage in the posterior fossa may produce some form of block so that the cerebral and spinal subarachnoid pressures do not equalize. Taylor and Whitfield (1936) described a case in which no blood reached the cerebrospinal fluid and suggested that sudden bleeding might result in a cerebellar pressure cone. Swelling of the cerebellum also can be associated with vascular disturbances of the lateral tegmentum of the pons as observed by Atkinson (1949) in operative occlusion of the anterior inferior cerebellar artery. Such mechanisms, however, have only been seen in fatal cases. The brain in Case 7 showed multiple infarctions in the pons, some of which were situated in the lateral tegmental region, dilatation of the lateral ventricles previously diagnosed by carotid angiography before death, blood in the fourth ventricle, and grooving of the cerebellar tonsils suggestive of herniation (Figs. 2, 3 , and 4).

Ventricular dilatation may result from the presence of firm blood clot in the fourth ventricle and subarachnoid space, and in the course of a week or so adhesions form in the posterior fossa as displayed at operation in Cases 3 and 4. In the former patient (Case 3) operative treatment was required to short circuit the obstruction by a ventriculostomy.

The true incidence of posterior fossa aneurysms is difficult to determine until bilateral vertebral angiography is carried out as a routine in cases of subarachnoid haemorrhage, when carotid angiography is negative. If the incidence is of the order of 10 to $15 \%$, as has been suggested, it would seem high enough to justify complete angiography. It will be realized that vertebral angiography will of course show up vascular lesions in the peripheral distribution of the vertebral supply beyond the subtentorial area to which this communication is confined, namely, the posterior cerebral trunks and their branches in the occipital lobes. The importance of this wider aspect of the investigation of patients with subarachnoid haemorrhage was emphasized by Spatz and Bull (1957) when, in 60 patients in whom bilateral carotid angiograms showed no lesion, 

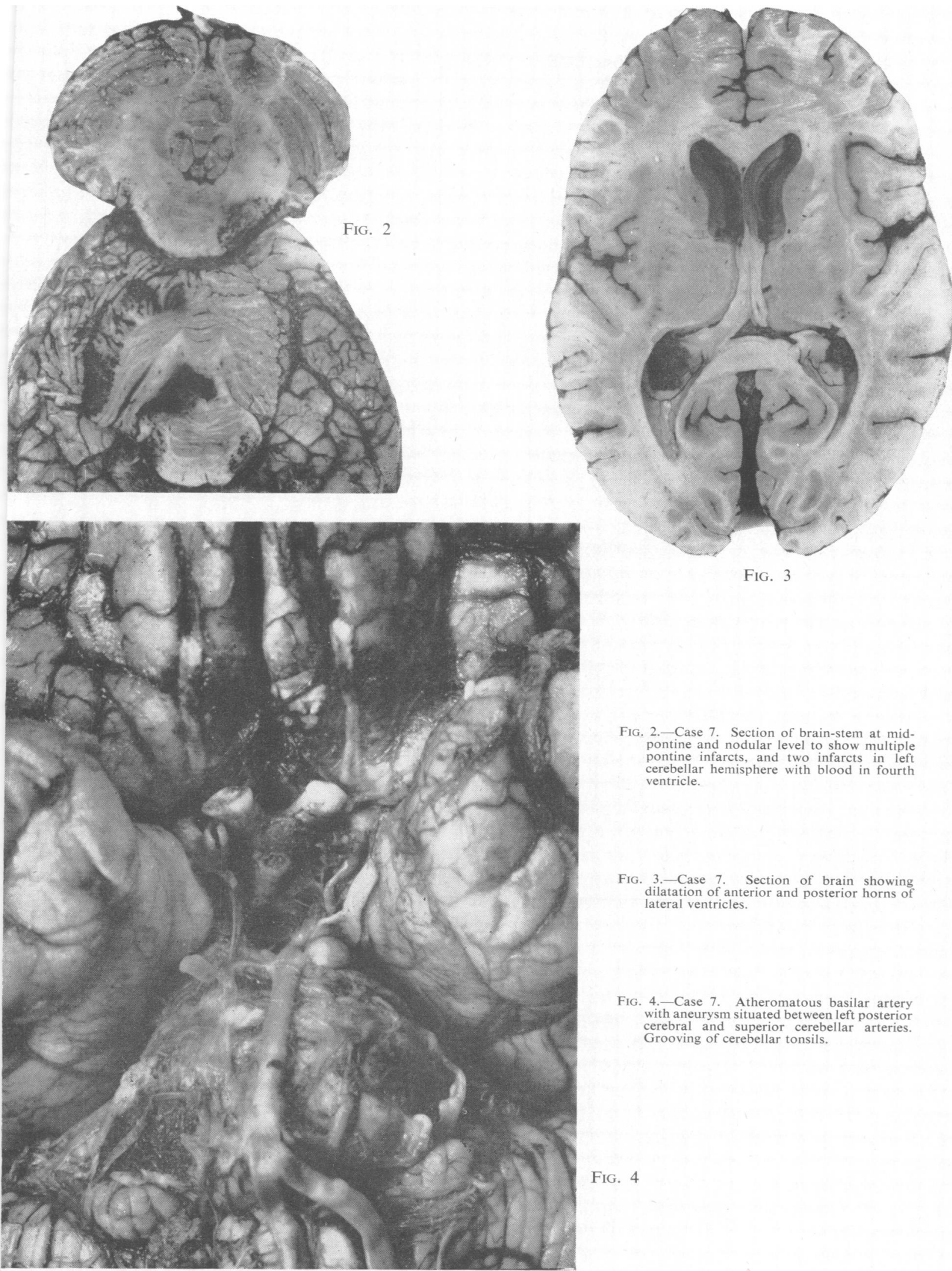

FIG, 2-Case 7. Section of brain-stem at mid pontine and nodular level to show multiple pontine infarets, and two infarcts in left pontine infarcts, and two infarcts in left
cerebellar hemisphere with blood in fourth ventricle.

FIG. 3

FIG. 3.-Case 7. Section of brain showing dilatation of anterior and posterior horns of lateral ventricles.

FIG. 4.-Case 7. Atheromatous basilar artery with aneurysm situated between left posterior cerebral and superior cerebellar arteries. Grooving of cerebellar tonsils. 
subsequent vertebral angiography showed a vascular cause in 16 cases $(26 \%)$ of which eight were angiomas and eight aneurysms.

The question arises whether the clinical features of aneurysms in the posterior fossa are sufficiently clear cut to justify vertebral angiography without undertaking bilateral carotid puncture first. Onset with weakness of the legs, fluctuations in consciousness, cenvulsive attacks with respiratory disturbances and hypersecretion of mucus, and minor brain-stem signs seem characteristic of subarachnoid haemorrhage due to these lesions, and recurrence of haemorrhage is common in the first three weeks. The difficulty is to distinguish between the disturbances due to haemorrhage in the region of the posterior fossa from those due to ruptured aneurysm of the anterior cerebral anterior communicating artery, which is a commoner cause of subarachnoid haemorrhage and is responsible for about $26 \%$ of cases. The anterior cerebral anterior communicating and basilar-vertebral aneurysms share in common certain clinical features, as haemorrhage from either irritates the brain-stem, though at different levels. Irrecoverable signs of neurological damage are commoner in the anteriorly situated aneurysms but time only can prove this in the individual patient. Both show the features of recurrent bleeds, and fluctuations in the level of consciousness. Unless neighbourhood signs in the cranial nerves indicate without doubt the lesion in the posterior fossa, the difference in incidence is so considerable that it would seem essential to carry out bilateral carotid angiography as an initial investigation. However, delay before proceeding to vertebral angiography should be minimal as a fatal bleed may occur any time in the posterior fossa, or irrecoverable damage to vision result if subhyaloid haemorrhages are prominent. An important point is that vertebral angiography should be bilateral, as although the basilar artery can be filled satisfactorily from either vertebral artery, unless both vertebral arteries are injected an aneurysm at the origin of the posterior inferior cerebellar artery may be missed.

The view has been expressed by Walton that vertebral angiography has the disadvantage of a higher incidence of thrombotic incidents which may be fatal. In the first six cases under consideration, angiography of carotid and vertebral vessels was carried out by a skilled radiologist. A sudden collapse with stertorous breathing followed com- bined carotid and vertebral angiography in Case 3, but on a painful stimulus he immediately recovered consciousness without any sequelae.

The prognosis of an individual haemorrhage is less grave than might be expected from the clinical features. Manifestations usually considered to indicate a poor prognosis, such as convulsions, stertorous breathing, and long tract signs, may be produced by irritation of the brain-stem without irrecoverable neurological damage, so have a less grave significance than when resulting from aneurysms elsewhere. The bilateral supply at the posterior and anterior extremity of the basilar artery may help to maintain the circulation.

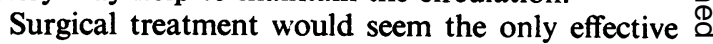
answer to subarachnoid haemorrhage in the posterior के fossa. The condition has a high natural mortality $\vec{O}$ due to recurrent bleeds and spontaneous recovery took place only in one elderly patient (Case 11) in $\vec{\omega}$ this series of 12 cases. Nothing therefore can be lost by embarking on vertebral angiography when carotid angiography is negative. If the lesion proves operable the results are good in experienced hands, $N$ even in the patients gravely ill from recurrenp haemorrhages at the time of surgical intervention.

\section{Conclusions}

Twelve cases of subarachnoid haemorrhage du to posterior fossa aneurysms are described. Tho incidence shows the same sex and age distribution a in supratentorial lesions.

The clinical features of ruptured subtentoria of aneurysms include weakness of the legs at the onset followed by headache and vomiting, fluctuation in the level of consciousness, with stertorous breathing and fits. Cranial nerve signs consist of subhyaloid haemorrhages, contracted pupils, nystagmus, and fifth, sixth, seventh, and eighth nerve pareses. Transient hemipareses occur in the limbs, sometimes with bilateral pyramidal signs. Electroencephalography (E.E.G.) may be of value by recording periodic bursts of slow waves suggestive of a brainstem lesion. Both vertebral arteries may require injection to detect the aneurysm. The lesions are dangerous because bleeding usually recurs unless surgical treatment is undertaken. All six patients, on whom craniotomy was performed with suitable operative treatment of the aneurysm, survived, and five of the six made good recoveries. Hydrocephalus may occur as a complication. 


\section{CASE HISTORIES}

\section{Group I}

Surgical treatment was used in Cases 1 to 6.

Case 1.-C.G., a woman aged 56, who had suffered from migraine all her life, experienced a sudden backache after which she became stiff and her eyes turned inwards. On coming round she complained of pain in the neck and right ear. She then vomited and developed neck stiffness so she was thought at first to have meningitis.

Neurological Examination.-The patient just responded to her name and painful stimuli. Neck rigidity was well marked. The right corneal reflex was diminished and both plantar responses were extensor.

The cerebrospinal fluid pressure was $250 \mathrm{~mm}$., and the fluid was heavily bloodstained. A right carotid angiogram showed no ab.ormality.

Course.-Two further coma-producing bleeds occurred with increased evidence of neurological damage. Examination in the third week showed a right sixth nerve paresis, hyperpathia in the first and second division of the right trigeminal nerve, and hypalgesia over the third division, deafness of the right ear, and a left upper motor neurone facial palsy with a left hemiparesis. Open right carotid and right vertebral angiograms were performed; the latter radiograph revealed an aneurysm on the right superior cerebellar artery.

Operation (V.L.).-This was performed on the sixteenth* day by the transtentorial approach. The tentorium was incised up to its free margin. An aneurysm $1 \mathrm{~cm}$. in diameter, lying immediately medial to the fifth nerve in a mass of clot, was found on the right superior cerebellar artery. The fifth nerve had to be divided to provide access. The artery was clipped on either side and the aneurysm excised.

Post-operative Progress. - The patient made an uninterrupted convalescence. Now six years later she leads a perfectly normal life, doing housework and shopping. She has never had another attack of migraine. Residual signs are those of right fifth nerve anaesthesia and slight contracture of the facial muscles on the same side.

The cessation of attacks of "migraine" suggest that the pain resulted from compression of the trigeminal nerve by the aneurysm. The intense pain in the right ear might be the result of disturbance of the nervus spinosus. This patient was the first in the series and vertebral angiography was performed late. The course shows the capacity for a patient to survive repeated haemorrhage around the brain-stem with recovery from a crossed hemiparesis. An important factor seems to be the absence of arteriosclerosis so that disturbances of the basilar circulation do not result in infarction of the pons.

* Time interval between most recent haemorrhage and operation.
Case 2.--C.C., a woman aged 49 , suddenly developed stiffness of the neck and back. She felt ill and so went into her neighbour's house where she vomited and complained of severe headache. Initially the pain was suboccipital in position but later spread forwards and became generalized.

Neurological Examination.-The next day she was confused, with neck rigidity, dilated pupils, and increased tendon jerks. The cerebrospinal fluid was at a pressure of $200 \mathrm{~mm}$. and was bloodstained. On admission to Maida Vale Hospital the pupils were widely dilated and responded poorly to light and accommodation. There was a slight spastic weakness of the left arm, and a generalized increase of the tendon jerks, maximal in the left arm. The left plantar response was flexor, but the right was extensor; the signs therefore suggested a bilateral lesion.

The electroencephalogram showed periodic synchronous outbursts of high-voltage slow activity, less in amplitude on the right side, suggesting anterior diencephalic compression.

Angiography.-Bilateral carotid angiography was negative. Right vertebral angiography showed spasm with no intracranial filling. Left vertebral angiography revealed a small saccular aneurysm at the upper end of the basilar artery giving rise to both superior cerebellar and pcsterior cerebral arteries.

Operation.-Operation (V.L.) on the fifteenth day by the subtemporal route confirmed that the aneurysm was situated exactly as the arteriogram had suggested. The sac was lying medial to the origin of the third nerve. Owing to the possibility of widespread ischaemia if the aneurysm was clipped across its base, it was packed around with muscle.

Post-operative Progress.-The patient had an uneventful convalescence and was leading a normal life without residual signs one year after the operation.

This procedure, although not radical, has been effective in preventing recurrence of the haemorrhage for the past 18 months.

Case 3.-J.R., a man aged 35, a motor mechanic, had experienced a right-sided posteriorly situated headache for four weeks. When driving his van objects suddenly looked out of focus, he felt cold, sick, and weak in the legs. He was unable to drive so stopped and opened the windscreen. He proceeded for another quarter of a mile when he was overcome by severe right-sided headache with vomiting but did not lose consciousness.

Neurological Examination.-There was neck rigidity, the right pupil at first was larger than the left, but the next day both pupils became contracted. The cerebrospinal fluid was at a pressure of $250 \mathrm{~mm}$. and was bloodstained.

The electroercephalogram (E.E.G.) was of rather low 
voltage, and the alpha rhythm was poorly developed. Periodic slow activity occurred in both occipital regions suggesting an occipital abnormality, possibly related to an aneurysm.

Course.-Bilateral carotid angiography was negative in the first week. Two further bleeds occurred subsequently, the second resulting in loss of consciousness for a few minutes with frothing at the mouth. On recovery he complained of an increase in headache and neck stiffness. Lumbar puncture showed an increase in pressure and fresh blood in the cerebrospinal fluid. A repeat left carotid angiogram 12 hours later was negative and a right vertebral angiogram showed poor filling of the basilar artery. Left vertebral angiography was then proceeded with and demonstrated an aneurysm arising from the posterior inferior cerebellar artery just above the posterior margin of the foramen magnum in the midline.

While still under the anaesthetic after angiography his respiration became stertorous and infrequent, so an endotracheal tube was passed. The respiratory rate went down to 8 per minute, the pupils were contracted but remained active, and the plantar responses became extensor in character. On stimulation of the supraorbital nerves there was free movement of the limbs, the patient became loquacious and said he felt fine. He made a rapid recovery from the anaesthetic, and the cerebrovascular spasm appeared to have passed off, but a further bleed occurred in the night.

Operation.-Operation was performed (V.L.) on the second day using a midline incision.

A bilocular aneurysm measuring $15 \times 7 \mathrm{~mm}$. was found arising from the left posterior inferior cerebellar artery lying between the cerebellar tonsils. The sac was mobilized and ligated, leaving a small vestibule joining the entry and exit vessels so as to avoid occluding them. The artery was such a large one that it was considered unwise to excise the segment of vessel bearing the aneurysm.

Post-operative Progress.-The patient developed dementia and ataxia due to a high pressure communicating hydrocephalus with a block at the tentorium and ventricular dilatation demonstrated by ventriculography. The condition was treated by anterior ventriculostomy.

One year later, his intellect and personality were said to be normal, the only abnormal signs being nystagmoid jerks and a little difficulty in balancing on one leg. He returned to light work with his original firm.

Pain in the head on the opposite side to the aneurysm proved a false localizing sign in this patient's case.

Case 4.-C.H., a woman aged 50, many years ago suffered an attack of left trigeminal neuralgia. She also had experienced two episodes of severe vertigo and headache, 18 and 12 months before the present illness. The first symptom was the sudden onset of weakness during a dancing lesson, so that she "flopped" to the ground and then developed occipital headache. She managed to get off the floor, and sit down on a chair but then lost consciousness for about two hours. On recovery she was aware of a sense of rotation and could not see anything although she realized that people were round her. She had a hazy memory of the rest of the night. At 6 a.m. she had to be dragged across the floor, and was helped into a car to take her home, where on arrival she was given an injection for migraine.

On admission to the local hospital the same day, she was complaining of severe headache, photophobia, and left sciatic pain.

Neurological Examination.-She showed neck stiffness, a contracted right pupil but minimal nystagmus on lateral deviation to the right. There was impaired vibration sense in the left leg and the left plantar response was extensor. Lumbar puncture showed a bloodstained fluid, but the pressure was not available.

Course.-After transfer to Maida Vale Hospital on the eighth day of illness there was slight neck stiffness. The cranial nerves were normal. Repetitive movements of the left hand and left leg were impaired, with ataxia in the heel-shin test. There was impaired vibration sense at the left internal malleolus, and some diminished appreciation of temperature in the right foot. The left plantar response was a weak extensor.

The electroencephalogram showed bursts of mixed theta and slow activity often bilateral, but always more marked on the left, and focal about the central regions.

Bilateral carotid angiography was normal. A right vertebral angiogram showed an irregularity of the right vertebral artery, suggestive of atheromatous involvement between atlas and axis. Left vertebral angiography revealed a saccular aneurysm about the origin of the posterior inferior cerebellar artery.

After angiography a right Horner's syndrome re appeared. The reflexes were reduced; the left plantar was a doubtful extensor. Later a slow nystagmus developed on lateral deviation to the left.

Operation.-Operation was performed (V.L.) on the nineteenth day under hypothermia, the patient in the sitting position.

Thick bands of arachnoid were found binding the ninth, tenth, and eleventh nerves to the seventh and eighth on the left side. A bilocular aneurysm indenting the pons arose by a neck from the left vertebral artery in juxtaposition to the posterior inferior cerebellar artery. The neck of the sac was occluded by a large clip leaving the posterior inferior cerebellar artery intact.

Post-operative Progress.-Angiography showed the clip in position. By 10 weeks after operation the patient was able to do her own housework and drive a car. Her only disability was some weakness in the left sternomastoid and trapezius muscles due to a spinal accessory paresis, which subsequently cleared up.

Case 5.-M.K., a woman aged 47, had suffered from frontal headaches all her life, usually associated with the monthly periods. Four days before admission she wakened with an unusually severe frontal headache. The following day she experienced a "cold ache" at the back of the right ear. Later the same day she felt dizzy, and became unconscious with stertorous respiration and jerking of the arms. On recovery of consciousness an hour later she complained of severe headache and pins and needles in both legs. 
Neurological Examination.-There was marked neck rigidity. Severe subhyaloid haemorrhages were present in both fundi, with a bilateral central field defect and reduction of visual acuity to counting fingers. There was bilateral ptosis. The tendon reflexes were increased, more on the right side, the right plantar response was extensor, the left was equivocal. The cerebrospinal fluid pressure was $140 \mathrm{~mm}$. and the fluid was heavily bloodstained.

The electroencephalogram (E.E.G.) was abnormal. The record showed no alpha activity. The most prominent feature was periodic runs of slow-wave activity predominantly frontal and very often focal in the left anterior temporal region.

Course.-Bilateral carotid angiography showed no abnormality. After a transient improvement for two days she suddenly had a generalized convulsion with stertorous, bubbly respiration, followed by a left hemiplegia, maximal in the leg. Some improvement in the hemiplegia took place followed by a further generalized convulsion. Both of these fits were associated with the presence of fresh blood in the cerebrospinal fluid. Right vertebral angiography revealed an aneurysm of the right vertebral artery.

Operation.-At operation 12 hours afterwards (V.L.) a saccular aneurysm $15 \times 8 \mathrm{~mm}$. was found on the right vertebral artery immediately after its entry into the cranial cavity. The proximal portion of the vertebral artery was occluded by a single tantalum clip.

Post-operative Course.-The patient developed a bulbar palsy following operation, probably due to ischaemia, which required tracheotomy. She made a slow recovery but nine months after operation she was able to do housework.

Residual signs consisted of wasting of the right side of the tongue, a right Horner's syndrome, and slightly increased jerks on the left side with ataxia of gait. The visual acuity of the left eye improved to $J 18$; the visual acuity of the right eye was counting fingers.

Case 6.-P.McM., a man 55, had a mild headache for four days which then suddenly became much worse. He vomited, was unable to use his legs, and gradually became semi-comatose.

Neurological Examination.-He could be aroused by verbal stimuli. Neck stiffness was minimal. The pupils were small but reacted to light, there was a left external rectus paresis. Movement was present in the limbs, and also a response to painful stimuli. Tone and tendon reflexes were increased in the left upper limb. The cerebrospinal fluid pressure was $150 \mathrm{~mm}$., with a bloodstained fluid. Bilateral carotid angiograms were negative. A left vertebral angiogram showed an aneurysm on the left vertebral artery, and spasm of the basilar artery.

Operation.-At operation on the tenth day (V.L.) an extensive subdural haematoma was evacuated, and the aneurysm was found arising as a saccular dilatation of the left vertebral artery, immediately after its entry into the skull. The distal portion of the vertebral and the posterior inferior cerebellar artery arose from its apex. The vertebral artery was completely occluded with a clip proximal to the sac.
Post-operative Course.-The day after operation he became stuporose, and developed a more marked left hemiparesis and dysphagia. A tracheotomy was required for the chest infection. He then made a steady recovery in spite of marked ataxia of gait which ultimately cleared up.

Left vertebral angiography showed good filling of the vertebral artery up to about $1 \mathrm{~cm}$. proximal to the clip. No filling of the aneurysm was obtained.

Fifteen months after operation residual signs consisted of a fine horizontal nystagmus, with reduction of appreciation of pain, temperature, and touch in the right leg below the knee, and reduction of joint sense in the toes. He was working full time on light work.

\section{Group II}

No surgical treatment was carried out in Cases 7 to 12 .

Case 7.-D.S., a woman aged 53, had suffered from headaches all her life, which during the last six years had been severe and stabbing in character, situated on the left side of the head. Ten years ago she had a loss of consciousness, and three years ago a proven subarachnoid haemorrhage.

She was found by her husband looking pale, and hanging on the sink to support herself. Later she developed severe occipital headaches and vomited.

Neurological Examination.-She was drowsy but cooperative. The fundi showed early papilloedema, the pupils were contracted, and she had a slight left spastic hemiparesis with bilateral extensor plantar responses. There was moderate neck stiffness. The cerebrospinal fluid was at $140 \mathrm{~mm}$. pressure and was heavily bloodstained. Two hours later she suddenly collapsed, and became comatose. The cerebrospinal fluid pressure was $200 \mathrm{~mm}$., and it contained an increase of blood.

Course.-She improved overnight but her breathing became stertorous and her chest "bubbly". The right arm then seemed more severely affected. Tone in all limbs was flaccid, with reduced tendon reflexes, the right more than the left. Both plantar responses were extensor. Bilateral carotid angiography showed gross atheromatous change, and possibly a small sac on the right internal carotid in the cavernous sinus. The left internal carotid artery was atheromatous in the same situation. Both anterior cerebral arteries were wideswept, indicating the presence of internal hydrocephalus.

If anything, her level of consciousness lightened but in spite of antibiotic treatment she died of a chest infection on the third day of illness, before vertebral angiography had been carried out.

Necropsy.-The lateral ventricles (Fig. 3) were moderately dilated. The pons was very full with fresh blood over its surface and over the middle peduncles; the lateral recesses and cisterna magna were free from blood. The basilar artery was markedly atheromatous and showed a saccular aneurysm $5 \mathrm{~mm}$. in diameter on the left side between the posterior cerebral and superior cerebellar arteries (Fig. 4). Section at the level of the mid pons showed an area of infarction on the right antero-lateral 
aspect. On the left side there was a similar area of infarction on the lateral aspect. Blood was present in the fourth ventricle and there was haemorrhage into a small infarcted area in the postero-lateral part of the pons on the left side. On the right there was no involvement of the cerebellum, but on the left side there was an area of infarction anteriorly, and another posteriorly, with blood in the sulci. Lower down in the pons at the level of the nodule there was another extensive infarct on the right side (Fig. 2).

Infarction of the pons due to atheroma of the basilar artery was probably the important factor in this patient's respiratory infection and death, and it is doubtful whether immediate vertebral angiography would have affected the treatment.

Case 8.-G.S., a woman aged 34, developed severe headache and became unconscious. The cerebrospinal fluid was at a pressure of $200 \mathrm{~mm}$., and heavily bloodstained. She recovered on the journey in the ambulance during transfer from the local hospital 12 hours after the haemorrhage.

Neurological Examination.-She was alert and cooperative. The right fundus was not seen due to haemorrhage, the left showed papilloedema. The tendon jerks were increased in the left limbs.

Course.-Bilateral carotid angiography was negative. Two days later the left eye became blind. A further haemorrhage occurred resulting in coma, inactive pupils, and twitching of the right arm. She recovered consciousness in 15 minutes, and showed a slight right facial palsy. Bilateral carotid angiography was again negative. She died on the sixth day after the haemorrhage.

At necropsy an aneurysm of the basilar artery was found situated between the anterior inferior and superior cerebellar arteries.

Case 9.-V.S., a woman aged 52, was found unconscious.

Neurological Examination.-Response to painful stimuli was just present. The pupils were fixed and unequal, the right larger than the left. There was a flaccid quadriplegia with absent jerks. The right plantar response was flexor, the left was equivocal. The cerebrospinal fluid was bloodstained.

Course.-Bilateral carotid angiography was normal.

Death occurred 10 hours after admission.

Necropsy. - A large aneurysm was situated at the midpart of the basilar artery with a large amount of clot extending to the foramen magnum.

Case 10.-R.R., a man aged 43, was heard by his wife to make a noise. She found him unconscious with his tongue protruding and his arms waving about. He recovered consciousness in half an hour, but was drowsy, irritable, and complained of frontal and occipital headache, and vomited.

Neurological Examination.-This showed neck rigidity and weakness of the right face and grip.

Course.-The cerebrospinal fluid was at a pressure of $300 \mathrm{~mm}$., and bloodstained. After a further haemorrhage he developed bilateral papilloedema, weakness of the right leg, and bilateral extensor plantar responses.
Bilateral carotid angiography on two occasions showed no abnormality. A left vertebral artery suggested an aneurysmal dilatation at the bifurcation of the basilar artery, with a possible haematoma displacing the right superior cerebellar artery.

He died on the 26th day and at necropsy the haemorrhage was thought to be due to a small aneurysm at the junction of the right vertebral and basilar arteries.

Case 11.-E.J., a woman aged 68 , had complained of headaches for seven years. She suddenly lost consciousness for 12 hours in one severe attack. On recovery she was drowsy, with occipital headache and neck stiffness.

Neurological Examination.-Three days later the patient was alert and cooperative but slightly confused. There were subhyaloid haemorrhages in the right fundus, the pupils were contracted and there were bilateral external rectus palsies. She had a right upper motor neurone facial weakness, and a left perceptive deafness. The blood pressure was $145 / 70 \mathrm{~mm}$. $\mathrm{Hg}$. There was massive albuminuria. The cerebrospinal fluid was uniformly bloodstained.

Course.-Bilateral carotid angiography and right vertebral angiography were negative. A left vertebral angiogram showed a small aneurysm of the left posterior inferior cerebellar artery. Three days later a right hemiparesis developed. Ventriculography was suggestive of a slight increase in the size of the ventricles. She ultimately made a good spontaneous recovery.

Case 12.-J.D., a man aged 62, suddenly developed weakness of the left leg, followed by severe frontal ando occipital headache. He vomited on several occasions, but did not lose consciousness. The right leg then became affected.

He was treated at home for two days and power recovered in both legs, but he complained of headache and was drowsy.

Neurological Examination.-Neck rigidity was present. The ocular signs consisted of retinal haemorrhages, loss of the nasal field left eye, contracted pupils, and a left sixth nerve palsy. He moved the right limbs more readily than the left. Blood pressure was $200 / 140 \mathrm{~mm}$. Hg. The heart was enlarged to the left. The cerebrospinal fluid pressure was $240 \mathrm{~mm}$., and the fluid heavily bloodstained.

Course.-Bilateral carotid angiography was suggestive of a possible aneurysm on the left posterior communicating artery. His condition deteriorated, and on tapping blood was found in both ventricles. He died on the seventh day.

Necropsy. - The brain and brain-stem were oedematous, the latter on the right side. A large haemorrhage was found in the right cerebellar hemisphere due to an aneurysm of the right posterior inferior cerebellar artery. 
We wish to thank Mr. Wylie McKissock for his kind permission to include Cases 8 to 12 from past records. We are also indebted to Dr. W. H. McMenemey for the pathological material from Case 7, and to the Photographic Department of the National Hospital for Figure 1.

\section{REFERENCES}

Atkinson, W. J. (1949). J. Neurol. Neurosurg. Psychait., 12, 137. Bakay, L.. and Sweet, W. H. (1953). J. Neurosurg., 10, 353 .

Brain. W. Russell (1955). Diseases of the Nervous System, 5th ed. Oxford University Press, London.

Cairns, H. (1952). Brain, 75, 109.

Dandy, W. E. (1944). Intracranial Arterial Aneurysms. Comstock Publishing Co. Ithaca, New York.

DeSaussure, R. Hunter, S. D. and Robertson, J. T. (1958). J. Neurosurg., 15, 385 .

Elkington. J. St C. (1958). Lancet, 2, 275.
French, L. A., and Haines, G. L. (1950). J. Neurosurg., 7, 156.

Kremer, M. (1958). Brit. med. J., 2, 121.

McDonald, C. A., and Korb, M. (1939). Arch. Neurol. Psychiat. (Chicago), 42, 298.

Norlèn G. and Barnum. A. S. (1953), J. Neurosurg., 10, 634.

Richardson, J. C., and Hyland, H. H. (1941). Medicine (Baltimore), 20, 1 .

Rizzoli, H. V., and Hayes, G. J. (1953). J. Neurosurg., 70, 550.

Robertson, E. G. (1949). Brain, 72, 150.

Schwartz, H. G. (1948). J. Neurosurg., 5, 312.

Spatz, E. L., and Bull, J. W. D. (1957). Ibid., 14, 543.

Taylor, A. B., and Whitfield, A. G. W. (1936). Quart. J. Med. (n.s.). 5,461 .

Tucker, J. S. (1958). Electroenceph. clin. Neurophysiol., 10, 405.

Uihlein. A., and Hughes, R. A. (1955). Surg. Clin. N. Amer., 35 , 1071 .

Walsh, L. S. (1957). Results of Treatment of Spontaneous Subarachnoid Haemorrhage. In Modern Trends in Neurology. Second Series, p. 119, ed. D. Williams. Butterworth, London.

Walton, J. N. (1956). Subarachnoid Haemorrhage. E. \& S. Livingstone, Edinburgh and London. 